\title{
OPEN
}

\section{1 \\ The Academic Book as Socially-Embedded Media Artefact}

\author{
Tom Mole
}

Abstract: For as long as it has existed in its modern form, the academic book has operated in what Jerome McGann calls 'a double helix of perceptual codes: the linguistic codes [...] and the bibliographical codes'. It unites a particular discursive genre with a particular material format. But now the double helix is starting to unravel as new, genetically modified digital formats force us to rethink what the academic book can be. This moment of media change meshes with shifts in the funding and assessment of research, developments in researchers' intellectual agendas and the challenges of Open Access. As disciplinary boundaries become more porous and scholarly outputs more varied, these changes will affect every stage in the life-cycle of the academic book.

Keywords: academic book of the future; academic codex; assessment; book history; format; funding monograph; hiring; PhD thesis; promotion; research output; socially-embedded media artifact; the academy

Lyons, Rebecca E. and Samantha J. Rayner (eds). The Academic Book of the Future. Basingstoke: Palgrave Macmillan, 2016. DOI: 10.1057/9781137595775.0006. 
For as long as it has existed in its modern form as a printed codex, the academic book has operated in what Jerome McGann calls 'a double helix of perceptual codes: the linguistic codes [...] and the bibliographical codes.' It unites a particular discursive genre with a particular material format. But now the double helix is starting to unravel as new, genetically modified digital formats force us to rethink what the academic book can be. This moment of media change meshes with shifts in the funding and assessment of research, developments in researchers' intellectual agendas and the challenges of Open Access. As disciplinary boundaries become more porous and scholarly outputs more varied, these changes will affect every stage in the life-cycle of the academic book, from research, collaboration and writing through publication, marketing, reading and preservation, whether it is a monograph, a scholarly edition, a collection of essays or a record of creative endeavour. Addressing the challenges the academic book of the future poses requires academics, librarians, publishers, funding councils, creative technologists, and research consumers to collaborate.

Intellectual work is starting to take on a variety of new forms, both as a result of scholars rethinking the best format in which to share their ideas, and as a result of external demands for transparent, measurable outputs. These shifts mandate a moment of self-reflection about the academic book. We can't afford to draw battle lines between the boosters of new technologies and the naysayers who cling to things as they were. Instead, we need a debate that is both historically informed and technologically literate. It should examine what new kinds of intellectual work the academic book of the future will make possible. But it should also consider what current features of the academic book are essential to excellent research and scholarship and should be preserved in the future. As we consider how field-changing work of lasting and transformative value in the humanities will be written, funded, rewarded, disseminated and preserved in a new media environment, we need to understand the affordances and limitations of the printed codex as an artefact of intellectual life. As the field that studies the production, circulation and reception of books as material artefacts in historical perspective, book history brings a distinctive approach to such debates. This short essay reflects this perspective by situating the academic book materially, institutionally and historically in order to understand what's at stake in its current transformation.

The current form of the academic book as a printed codex constrains arts and humanities researchers in various specific ways: scholars of 
screen media cannot include clips from films, TV programmes or computer games; cultural geographers cannot include dynamic interactive maps; art historians and scholars of visual culture cannot typically include large numbers of colour images; musicologists cannot include audio; researchers working with large data-sets cannot typically publish the data on which their arguments depend; textual editors cannot include all the documentary evidence they have assembled; scholars engaged in creative and performing arts research cannot always document their practice adequately. The processes of assessment and production are slow and post-publication revision is difficult. It should be possible to overcome some of these constraints when the academic book no longer (only) takes the form of a printed codex. This means that the academic book of the future must do more than remediate the printed codex, replicating the experience of paper books in digital formats as current e-readers typically do.

Even as the constraints of the printed codex become harder to ignore, systemic factors combine to pressure scholars to write more of them. Many North American universities that would not have required a monograph for tenure in humanities disciplines a decade ago now routinely look for one, while some that have always expected a monograph for tenure now expect to see significant progress towards a second book. In the UK, Research Excellence Framework (REF) panels tend to value monographs highly (and arguably to undervalue edited collections and scholarly editions). Monographs feature prominently in hiring and promotion decisions, increasing the pressure on scholars at all career stages to think of their work in terms of monograph publication. ${ }^{2}$ At the same time, many academic presses are publishing fewer monographs especially in certain disciplines such as modern languages - and are printing fewer copies of the monographs they do publish. Libraries buy fewer monographs, largely because they spend increasing fractions of their shrinking acquisitions budgets on bundled scientific journals published for profit. In these conditions we have to ask what the academic book is for.

Despite its limitations, the monograph has become a gold standard in many humanities disciplines for good reasons. The academic book's rise to the centre of our intellectual lives has its own long history. The codex and the architecture of the page have been built into the fabric of the academy and the careers of those who work there ever since the university system developed in the twelfth century. ${ }^{3}$ The advent of printing 
helped produce the Renaissance's flowering of humanistic scholarship and the transformation of the academy it entailed. ${ }^{4}$ With the massive proliferation of printed books at the end of the eighteenth century the modern research university took shape, as Chad Wellmon has argued, as an institution to control the production, dissemination, organisation and storage of books. ${ }^{5}$ As the modern disciplinary organisation of knowledge emerged in the nineteenth century and then the higher education sector expanded in Europe and North America in the twentieth, the monograph became the most valued form of research output and, eventually, the signal achievement allowing access to senior positions in the profession. In these contexts, the monograph aimed to be the definitive statement of an author's work on a well-defined topic, reflecting a relatively ambitious research programme, typically carried out over several years, informed by a comprehensive grasp of existing work in the field, which reflected sustained intellectual effort at the highest level and aspired to produce a lasting contribution to knowledge.

Understanding the history of the academic monograph shows us that the printed academic codex is a socially-embedded media artefact, whose significance lies as much in the institutional and professional structures it helps to produce as in the technology of print itself. ${ }^{6}$ The academic book has fostered assessment practices that assure quality, such as peer review, and add value, such as publishers' editing, design, layout, indexing and so on. These structures ensure that the prestige of the academic book is justified and they must be replicated or revised in the digital environment. The academic book has given rise to professional protocols that inform credentialing, hiring, promotion and reward decisions. While a $\mathrm{PhD}$ thesis differs in important ways from a published book, the shape of the doctorate mirrors the form of the monograph: a doctorate is in large part a course of training in how to write a book. The monograph has been connected to a marketing and dissemination apparatus that allows it to reach its audience effectively. It benefits from institutional structures and communities of practice, such as libraries within and beyond universities, that ensure its long-term preservation and accessibility. The academic book is and will remain embedded in social, professional and institutional structures that make it an effective research output. Changing the form of the academic book will mean changing those structures in order for them to remain fit for purpose. If our current moment of media change is to enrich and empower humanistic scholarship rather than cheapening it, then, we need to think 
about how new forms of output will force us to revise our institutional structures, our forms of training and credentialing, our narratives of professional development, our models of research practice, our understandings of collaboration, and our forms of knowledge production, circulation and archiving.

Not all of the academic book's future users will be human. As machinereading, text-mining, online 'social annotation' and related approaches come of age, the academic book will need to be optimised for new reading techniques. This creates particular challenges where the book includes non-textual content. As humanities researchers increasingly want to zoom in and out between 'distant' and 'close' reading protocols, the academic book will need to facilitate scaleable reading.? We must ensure that academic books are designed today in such a way that they will be findable, citeable and readable in the long term, using as yet undeveloped tools. Scholars in the future will want not only to write different kinds of books, but also to discover, study and interrogate books in new ways. The academic book of the future will need to be future-proof.

We can read printed books that are 600 years old. The academic book of the future may not remain useable for so long. The printed codex marries hardware (the paper and ink) and software (the words and ideas). This makes it one of the most durable data-storage technologies ever devised. This is not the case for electronic formats, where the 'content' needs to be readable on new devices powered by upgraded software. Most printed books exist relatively well in regimes of benign neglect. With reasonably constant temperature and humidity levels, and without overexposure to light or moisture, they remain readable for centuries. ${ }^{8}$ The same is not true of electronic formats, which often become irrecoverable after only a few years due to obsolescent hardware and software. We therefore need to consider who will bear the ongoing responsibility and cost of maintaining long-term access and usability of academic books created in digital formats, and the datasets associated with them. This means remixing the division of labour that currently exists among faculty, publishers, and librarians.

As the academic book of the future takes shape, we will also need to engage seriously with the concerns raised in many quarters that digital media make sustained intellectual work more difficult, even while they facilitate research in some respects. Drawing on the neuroscience of reading, some commentators have asked whether the kind of long-form linear argumentation that has been the gold standard of humanistic 
scholarship will be sustainable in digital formats or will find readers among digital natives. ${ }^{9}$ There is some evidence that reading on the screen produces lower levels of comprehension and retention compared with reading on the page, at least among the current generation of university students. ${ }^{10}$ The kind of sustained absorptive reading the humanities value and academic monographs demand may simply be harder on screen, especially on internet-enabled devices with their endless potential for distraction.

Finally, there is a politics of the academic book. Those of us employed in the academy, especially in the UK, are increasingly asked to work faster, to submit to greater scrutiny, to be more responsive to agendas we didn't set, and to undertake research that will produce immediate, direct and measurable impacts beyond the academy. The academic monograph as a form, with its long gestation, its in-built reflection on its own working assumptions, its resistance to quick reading or easy summary and its aspiration to long-term significance, offers some resistance to these demands. The academic book of the future might allow us to work faster and more responsively thanks to the affordances of digital media. We must learn to benefit from these advantages, without accepting uncritically the managerialist insistence on accelerated production, the demand to be responsive and 'relevant', or the wider culture of endless distraction, soundbites and clickbait.

Scholars in the arts and humanities have already begun to reflect on how shifts in the media ecology will transform their work. ${ }^{11}$ We now face the challenge of imagining how the academic book of the future will continue to make transformative contributions to knowledge. As new formats for the long-form output emerge, they have the potential to transform not only the way we disseminate our research but also the ways in which we conceive and produce it. Innovations from within arts and humanities scholarship and pressures from outside are combining to produce a shift in the forms of scholarly communication that may come to seem as significant as the introduction of print itself. Many people have a stake in the academic book of the future. If the UK can innovate in this area it will compete internationally for research talent, student recruitment and intellectual leadership. At the same time, we need to ensure that the most valuable qualities of the academic book as printed codex migrate to the new media environment without being devalued. If we get it right, new understandings of what a book can be will enable academic work that at present remains unwritten, indeed unthought. 


\section{Notes}

1 Jerome McGann (1991) The Textual Condition (Princeton, NJ: Princeton University Press), p. 77.

2 See the report of the MLA Ad Hoc Committee on the Future of Scholarly Publishing: http://www.mla.org/resources/documents/issues_scholarly_pub/ repview_future_pub, date accessed 10 September 2015.

3 Bonnie Mak (2011) How the Page Matters (Toronto, ON: University of Toronto Press).

4 Elizabeth Eisenstein (1980) The Printing Press as an Agent of Change (Cambridge: Cambridge University Press).

5 Chad Wellmon (2015) Organizing Enlightenment: Information Overload and the Invention of the Modern Research University (Baltimore, MD: Johns Hopkins University Press).

6 Lucien Febvre and Henri-Jean Martin (1976) The Coming of the Book: The Impact of Printing, 1450-1850, trans. D. Gerard (New York: Verso); Adrian Johns (2000) The Nature of the Book: Print and Knowledge in the Making (Chicago: University of Chicago Press).

7 See, e.g., Franco Moretti (2005) Graphs, Maps, Trees: Abstract Models for a Literary History (New York: Verso) and (2013) Distant Reading (New York: Verso).

8 An exception, of course, is books printed on acidic paper, which becomes brittle over time.

9 Nicholas Carr (2011) The Shallows: What the Internet is Doing to Our Brains (New York: Norton); Maryanne Wolf (2008) Proust and the Squid: The Story and Science of the Reading Brain (New York: HarperCollins).

10 Naomi Baron (2015) Words Onscreen: The Fate of Reading in a Digital World (Oxford: Oxford University Press).

11 Among many examples, see Andrew Piper (2012) Book Was There: Reading in Electronic Times (Chicago: University of Chicago Press); Matthew Kirschenbaum (2008) Mechanisms: New Media and the Forensic Imagination (Boston: MIT Press); and Marilyn Deegan and Kathryn Sutherland (2009) Transferred Illusions: Digital Technology and the Forms of Print (London: Ashgate).

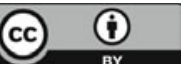

Except where otherwise noted, this work is licensed under a Creative Commons Attribution 4.0 International License. To view a copy of this license, visit https://creativecommons.org/version4 